\title{
ANÁLISE DE 1 CORÍNTIOS 2,1-5: PAULO DE TARSO EM COMPARAÇÃO COM OS ESTOICOS SOBRE "SABEDORIA"
}

\author{
Diogo da Luz ${ }^{1}$
}

\begin{abstract}
RESUMO
Neste artigo elaboramos um estudo exegético de 1C oríntios 2,1-5 com o objetivo de cotejar com a visão estoica de sabedoria. Na perícope em questão, assim como no contexto de 1 Coríntios, Paulo torna explícita sua defesa de superação do ideal de sabedoria, pois defende que esta ainda se encontra no nível humano, não divino. Ao fazer isso, o apóstolo se opõe a uma das principais linhas filosóficas de sua época, o estoicismo, uma vez que os estoicos têm por finalidade justamente a sabedoria, ou mais objetivamente, a vida sábia.
\end{abstract}

Palavras-chave: Paulo. Coríntios. Estoicos. Sabedoria.

\begin{abstract}
In this article we elaborated an exegetical study of 1 Corinthians 2,1-5 with the objective of comparing with the stoic view of wisdom. In the pericope, as in the context of 1 Corinthians, Paul makes explicit his defense of overcoming the ideal of wisdom, because he argues that it is still at the human level, not divine. In doing so, the apostle opposes one of the main philosophical lines of his time, stoicism, since stoics are intended for wisdom, or more objectively, wise life.
\end{abstract}

Keywords: Paul. Corinthians. Stoics. Wisdom.

\section{Considerações Iniciais}

A primeira carta aos coríntios, na parte que diz respeito ao presente estudo, apresenta uma objeção ao ideal de sabedoria. Ao fazer isso, Paulo pretende demonstrar que sua pregação está para além das pretensões da sabedoria humana, pois diz respeito a algo superior, a saber, ao poder de Deus.

Para contrastar essa defesa paulina com a perspectiva estoica, inicialmente faremos uma breve exposição do estoicismo no que diz respeito à sabedoria. Logo depois, passaremos à análise de 1 Cor 2,1-5, abrangendo

${ }^{1}$ Doutorando em Filosofia pela PUC/RS.

E-mail: diogoftcons@hotmail.com. ORCID: 0000-0001-8647-7253. 
passagens bíblicas próximas e relacionadas, assim como situando as palavras de Paulo às questões da época.

\section{Estoicismo: contextualizando pela física}

Para compreender o estoicismo na Roma antiga é imprescindível considerar as teses principais que estabeleceram esse movimento filosófico e espiritual. Elas foram lançadas em Atenas, em meio ao caldo cultural e filosófico grego, tendo profundas ligações com filósofos como Heráclito², Sócrates e Antístenes ${ }^{3}$, tanto quanto com poetas como Homero ${ }^{4}$ e Hesíodo ${ }^{5}$. Em função disso, o estoicismo do período romano traz em seus elementos basilares essa perspectiva grega.

Para Zenão de Cítio, fundador do estoicismo, a natureza não é simplesmente obra de uma divindade: na natureza está a própria divindade. Não há separação entre autor e obra, ambos dizem respeito a algo unificado que se expressa em cada detalhe da natureza $(S V F, \mathrm{I}, 111,113)$. Além disso, o natural não é apenas o que talvez alguém poderia compreender hoje eliminando a razão e o âmbito espiritual: pelo contrário, o natural para os estoicos é tudo o que há no cosmos, incluindo nisso a razão e o espírito, ou como eles poderiam dizer, um espírito racional na natureza. Há o âmbito espiritual na medida em que o pneûma (sopro/espírito) divino permeia tudo no cosmos, estabelecendo a coesão necessária a cada corpo material, e há a racionalidade na medida em que esse pneûma é logóico, ou seja, é o lógos cósmico em atuação, que traduzimos por "razão" (dentre as diversas possibilidades de tradução que são possíveis para esse termo) (DL VII, 156).

O pnêิma se desdobra na natureza desde os elementos mais simples até os mais complexos, de maneira que seus graus de tensão formam uma escala na natureza (scala naturae): as pedras e os demais minerais, por exemplo, já são uma disposição (héxis) específica; nas plantas, por sua vez, passamos a encontrar características vegetativas (phýsis) tais como cresci-

\footnotetext{
${ }^{2}$ Por exemplo, em AULO GÉLIO. Noites Áticas, VII, 1. Ou de forma textual no Stoicorum Veterum Fragmenta, I, 141 (na sequência, será adotada a abreviação SVF para essa obra).

${ }^{3}$ Por exemplo, em DIÓGENES LAÉRCIO. Vidas e doutrinas dos filósofos ilustres, I, 1315 (na sequência, será adotada a abreviação $D L$ para essa obra).

${ }^{4} S V F$, I, 274, por exemplo.

${ }^{5} S V F$, I, 539, por exemplo.
} 
mento, nutrição e transformação; em outro grau, nos animais, acrescentamse as capacidades anímicas (psykhé) de percepção, representação e impulso; por fim, nos seres humanos as almas adquirem a potência racional ( $S V F$ II, 458).

\section{O âmbito humano}

Tendo feito esse contexto, é possível perceber com mais clareza a afirmação estoica de que os seres humanos são fragmentos da divindade, uma vez que são seres com capacidade racional, comungando assim com a divindade, e estando bem harmonizados a ela quando no uso reto da razão (orthòs lógos). É a partir disso que podemos compreender o seguinte excerto do De Legibus de Cícero (I, 22-23) que expressa completamente o pensamento estoico:

Com efeito, o que é mais divino, não direi apenas no homem, mas em todo o céu e a terra, do que a razão? E a razão, quando totalmente desenvolvida e aperfeiçoada, merece acertadamente ser chamada de sabedoria. Logo, se se observa que não há nada superior à razão, e que esta se encontra tanto no homem quanto em Deus, resulta daí que a razão é o vínculo da primeira associação que se estabelece entre o homem e Deus.

Quid est autem, non dicam in homine, sed in omni caelo atque terra, ratione diuinus? Quae quom adoleuit atque perfecta est, nominatur rite sapientia. Est igitur, quoniam nihil est ratione melius, eaque $<$ est $>$ et in homine et in deo, prima homini cum deo rationis societas.

Sendo assim, a relação com o divino se dá pela razão, que em forma mais madura e aperfeiçoada é denominada sabedoria. Em vista disso, a sabedoria, como entendida pelos estoicos, é o que há de mais importante e divino. Ou melhor: a vida que se harmoniza à divindade é a vida com sabedoria, isto é, a vida do sábio, pois a sabedoria que se tem é na vida, no cotidiano, nas ações de fato. Nesse caso, a sabedoria inclui também conhecimento prático, phrónessis (SVF III, 257), não estando este dissociado da contemplação (theoría).

Além do mais, quanto ao uso do termo "sabedoria" nas obras romanas, como se pode encontrar em Sêneca e Cícero, verifica-se que frequentemente esta se referia à filosofia, demonstrando a íntima relação entre esses 
termos nas referências intelectutais da época. A palavra sabedoria (sapientia), portanto, estava associada à filosofia ${ }^{6}$.

Após essa breve contextualização estoica, passemos agora à interpretação bíblica em questão.

\section{Em torno de 1 Coríntios 2,1-5.}

Eu mesmo, quando fui ter convosco, irmãos, não me apresentei com o prestígio da palavra ou da sabedoria para vos anunciar o mistério de Deus. Pois não quis saber outra coisa entre vós a não ser Jesus Cristo, e Jesus Cristo crucificado. Estive entre vós cheio de fraqueza, receio e tremor; minha palavra e minha pregação nada tinham da persuasiva linguagem da sabedoria, mas eram uma demonstração de Espírito e poder, a fim de que a vossa fé não se baseie sobre a sabedoria dos homens, mas sobre o poder de Deus $(1 \text { Cor } 2,1-5)^{7}$.

\section{Tempo, lugar e contexto}

A primeira carta de Paulo aos Coríntios provavelmente foi escrita entre 53 e 54 d.C, na cidade de Éfeso, após Paulo ter estado por volta de dezoito meses em Corinto. Durante suas primeiras semanas na cidade de Corinto, Paulo exerceu seu ofício manual de fabricante de tendas até ser posteriormente reconhecido como pregador. Paulo chega a Corinto no ano 50 d.C., fisicamente abatido e espiritualmente cansado de sua experiência em Atenas, onde conseguiu poucos convertidos, tendo sido deixado de lado pela plateia intelectual. Na nova cidade, ele reconhece um compatriota judeu chamado Áquila que, junto com sua esposa Priscila, acolhem o apóstolo e o apoiam em sua propagação religiosa (At 18,2.18).

Inicialmente, Paulo concentrou-se na sinagoga, mas posteriormente foi proibido de entrar. Com isso, passou a realizar suas reuniões em uma casa ao lado, a casa de um gentio (Justo). Nessa casa, Paulo fez muitos contatos e, de fato, muitos passaram a crer e foram batizados.

\footnotetext{
${ }^{6}$ Conforme, entre outras passagens, SÊNECA. Cartas, 104, 19 e CÍCERO. De Finibus, I, 1-3.

${ }^{7}$ Tradução da Bíblia de Jerusalém. As demais citações bíblicas, quando não especificadas, seguem dessa fonte.
} 
Após sua estada em Corinto, Paulo recebe notícias de dissensões, o que o faz escrever os primeiros quatro capítulos da primeira carta aos Coríntios.

Corinto era uma cidade próspera, onde circulavam muitas pessoas, pois era um local portuário. No entanto, assim como outras cidades portuárias, Corinto era uma cidade muito liberal, a tal ponto que os gregos cunharam a expressão korinthiazein para expressar ações consideradas indecorosas. Havia cultos pagãos ao sexo (sacerdotisas de Afrodite) e ao corpo masculino (devoção a Apolo), sendo este último ocasionador de práticas homossexuais.

É, portanto, nesse contexto de divisões e de ações consideradas indecorosas na igreja de Corinto que Paulo tenta inserir suas palavras epistolares para reafirmar o que defendeu ser a real dimensão do poder de Deus (PRIOR, 1993, p. 11-13).

\section{$O$ texto antecedente: 1 Cor $1,1-31$}

O início de 1 Coríntios refere-se à desunião dos coríntios, uma vez que se dividiam afirmando "eu sou de Paulo" ou "eu sou de Apolo" ou "eu sou de Cefas" ou "eu sou de Cristo". Paulo, por sua vez, pretende mostrar a incongruência dessa divisão, uma vez que Cristo é um só, e que o batismo não é em nome de quem batiza, mas em nome de Cristo (1,11-16).

Paulo ressalta que eles foram chamados à comunhão com Cristo. Afirma que o testemunho de Cristo se tornou firme neles, e que foram cumulados de todas as riquezas em Cristo, "todas as da palavra e todas as do conhecimento" $(1,4-5)$.

Esse apelo à comunhão é trazido para que eles não se vangloriassem uns em relação aos outros, pois a glória nunca é do homem, mas de Deus (1,29-31). Nesse contexto, Paulo afirma que é por Deus que eles são em Cristo, "que se tornou para nós sabedoria proveniente de Deus, justiça, santificação e redenção (1,30-31).

Dado o ambiente de cultura helenística em Corinto, cultura essa aberta a debates em busca de sabedoria, Paulo faz sua defesa da comunhão 
(koinonía) em Cristo por meio da distinção entre sabedoria do mundo e sabedoria cristã.

\section{O texto subsequente: 1 Cor 2,$6 ; 3$}

Logo após a nossa perícope delimitada para estudo, Paulo ressalta que a sabedoria divina não é deste mundo $(2,6)$. A linguagem que expressa essa sabedoria se dá segundo o que o Espírito (pneûma) ensina, “exprimindo realidades espirituais em termos espirituais" $(2,13)$. Porém, Paulo afirma que não pôde falar aos coríntios como a homens espirituais, uma vez que eles ainda são carnais, e demonstra isso evidenciando que eles criam cisões entre si mesmos quando agem de maneira ainda meramente humana, dividindo-se por invejas e rixas quando afirmam "eu sou de Paulo" ou "eu sou de Apolo" $(2,10-3,4)$.

Ao final, em 3,21-23, Paulo conclui que eles não devem então procurar nos homens motivo de orgulho, pois eles não pertencem aos homens, mas a Cristo.

\section{Análise da Perícope 1Cor 2,1-5}

\begin{tabular}{|c|c|c|}
\hline $\begin{array}{l}\text { BÍBLIA DE JERUSA- } \\
\text { LÉM }\end{array}$ & $\begin{array}{l}\text { BÍBLIA } \\
\text { NOVO TESTAMENTO } \\
\text { vol. II } \\
\text { Apóstolos, Epístolas, Apoca- } \\
\text { lipse } \\
\text { (Trad. Frederico Lourenço) }\end{array}$ & TEXTO EM GREGO \\
\hline $\begin{array}{l}1 \text { Eu mesmo, quando fui } \\
\text { ter convosco, irmãos, não } \\
\text { me apresentei com o pres- } \\
\text { tígio da palavra ou da sa- } \\
\text { bedoria para vos anunciar } \\
\text { o mistério de Deus. }\end{array}$ & $\begin{array}{l}1 \text { Também eu, quando fui ter } \\
\text { convosco, irmãos, não che- } \\
\text { guei com superioridade de } \\
\text { linguagem ou de sabedoria, } \\
\text { anunciando-vos o mistério de } \\
\text { Deus. }\end{array}$ & 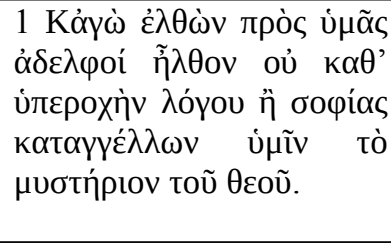 \\
\hline $\begin{array}{l}2 \text { Pois não quis saber outra } \\
\text { coisa entre vós a não ser } \\
\text { Jesus Cristo, e Jesus Cris- } \\
\text { to crucificado. }\end{array}$ & $\begin{array}{l}2 \text { Não julguei saber outra } \\
\text { coisa entre vós a não ser Je- } \\
\text { sus Cristo; e este, crucifica- } \\
\text { do. }\end{array}$ & 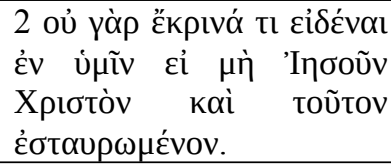 \\
\hline $\begin{array}{l}3 \text { Estive entre vós cheio de } \\
\text { fraqueza, receio e tremor; }\end{array}$ & $\begin{array}{l}3 \text { E eu, em [posição de] fra- } \\
\text { queza, receio e grande temor, } \\
\text { estive entre vós. }\end{array}$ & 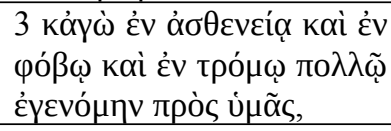 \\
\hline $\begin{array}{l}4 \text { minha palavra e minha } \\
\text { pregação nada tinham da } \\
\text { persuasiva linguagem da } \\
\text { sabedoria, mas eram uma } \\
\text { demonstração de Espírito } \\
\text { e poder, }\end{array}$ & $\begin{array}{l}4 \text { A minha palavra e a minha } \\
\text { pregação não [se baseavam] } \\
\text { numa persuasão de sabedo- } \\
\text { ria, mas em demonstração de } \\
\text { espírito e de poder, }\end{array}$ & 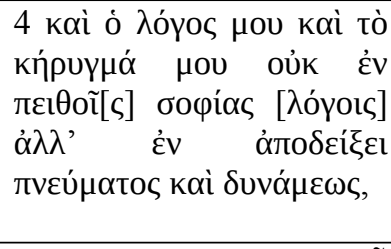 \\
\hline 5 a fim de que a vossa fé & 5 para que a vossa fé não es- & 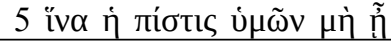 \\
\hline
\end{tabular}




\begin{tabular}{|c|c|c|}
\hline $\begin{array}{l}\text { não se baseie sobre a sabe- } \\
\text { doria dos homens, mas so- } \\
\text { bre o poder de Deus. }\end{array}$ & $\begin{array}{l}\text { tivesse [baseada] em sabedo- } \\
\text { ria de homens, mas em poder } \\
\text { de Deus. }\end{array}$ & 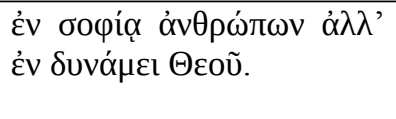 \\
\hline
\end{tabular}

2,1: "Eu mesmo, quando fui ter convosco, irmãos, não me apresentei com o prestígio da palavra ou da sabedoria para vos anunciar o mistério de Deus".

Paulo coloca a si mesmo com exemplo, com o objetivo de mostrar qual a atitude correta. Ele afirma que não utilizou o recurso de uma linguagem (lógos) elevada, pois não é isso que anuncia a divindade. Podemos entender aqui a elevação da linguagem como um bem falar, com um vocabulário adequado, frases bem colocadas e uma dinâmica persuasiva, típicos da educação retórica de seu tempo. Nesse período, a retórica fazia parte de uma boa educação, e a Paulo certamente foi oportunizado esse aprendizado. Embora Paulo tenha usado da retórica em suas cartas, inclusive aplicando alguns lugares comuns (tópoi) retóricos muito utilizados (FORBES, 2003, p. 113-146), ele aqui afirma que esta não foi sua prática quando esteve pessoalmente em Corinto.

Da mesma forma, em sua apresentação ele afirma não ter apelado à autoridade do conhecimento, da sabedoria (sophía) enquanto ciência (episté$m \underline{e})$, ou seja, ele não buscou se elevar por meio do intelecto, articulando razões tal qual um filósofo ou um físico, pois afirma que o mistério de Deus não é acessado dessa forma. Nesse caso, ele se diferencia dos filósofos, principalmente dos que ele encontrou em Atenas, assim como dos gnósticos que entendiam que o mistério divino (mystérion - termo que lhes era típico) poderia ser acessado pelo conhecimento humano (MAZZAROLLO, 2000, p. 124).

2,2: Pois não quis saber outra coisa entre vós a não ser Jesus Cristo, e Jesus Cristo crucificado.

Paulo aqui demonstra que sua pregação não se estabeleceu por meio de seus atributos pessoais, mas através do que julgava saber de Jesus Cristo. Nesse caso, preferimos a tradução de Frederico Lourenço à da Bíblia de Jerusalém, pois esta última, ao traduzir ékrina por "quis", deu um sentido de intencionalidade a um verbo relacionado à distinção, separação, juízo (krísis). Dessa forma, Paulo mantém a implicação epistêmica da frase anteri- 
or, mas agora explicitando a sua fundamentação: Jesus Cristo e o advento de sua crucificação.

\section{2,3: Estive entre vós cheio de fraqueza, receio e tremor;}

Paulo relembra que estava abatido no momento em que esteve com os coríntios a ponto de deixar clara a grande amplitude de sua temeridade. Portanto, demonstra que não foi a partir da altivez de sua figura, ou seja, da sua força pessoal, que sua pregação se fez. Complementando as frases anteriores, Paulo dá um passo mais específico em sua eliminação das fontes de prestígio do gênero humano, passando a deixar claro que o poder que foi manifestado em Corinto não partiu nem de potências individuais nem humanas.

2,4: minha palavra e minha pregação nada tinham da persuasiva linguagem da sabedoria, mas eram uma demonstração de Espírito e poder,

Nesse momento, Paulo tira o foco da sua pessoa e coloca nas suas palavras e pregação, mais especificamente na forma como elas ocorreram. Nelas não havia, segundo ele, nada de discurso de sabedoria (sophía), ou seja, nada daquilo que poderia ser encontrado em alguma destacada cultura grega da cidade de Corinto ${ }^{8}$. A persuasão (peithó), tão visada no discurso retórico, é associada aqui também à sabedoria, que, por sua vez, é a finalidade da ciência e da filosofia ${ }^{9}$. Assim como em outros momentos, Paulo visa se opor aos discursos que apregoavam o empoderamento daqueles que confiam nas suas próprias potências racionais, intelectivas, uma vez que eles não são ainda espirituais, mas psíquicos (psykhikós), estando ainda no âmbito humano, não divino ${ }^{10}$. Como Paulo dirá mais adiante, os homens psíquicos consideram loucura achar que o espírito vem de Deus $(2,14)$.

\footnotetext{
8 "Os judeus pedem sinais, e os gregos andam em busca de sabedoria" $(1,22)$;

9 Àquela época, ciência e filosofia não estavam ainda desmembradas como em nosso contexto contemporâneo.

${ }^{10}$ Paulo também faz distinção entre corpo psíquico e corpo espiritual, sendo que este último surge após a ressurreição. "Se há um corpo psíquico, há também um corpo espiritual. Assim está escrito: o primeiro homem, Adão, foi feito alma vivente; o último Adão tornouse espírito que dá a vida. Primeiro foi feito não o que é espiritual, mas o que é psíquico; o que é espiritual vem depois. O primeiro homem, tirado da terra, é terrestre. O segundo homem vem do céu" (1Cor 15,44-47).
} 
Além disso, Paulo também se separa aqui da sabedoria judaica, que pode ser vislumbrada tanto na sabedoria de Salomão quanto na filosofia judaica (como a de Fílon de Alexandria) (MAZZAROLLO, 2000, p. 125).

Em contraposição, Paulo afirma que sua palavra e pregação eram uma demonstração (apódeixis) de espírito (pneûma) e poder (dýnamis). Nesse caso, o que ele faz é uma exposição, não uma construção lógico-argumentativa; é, a saber, uma exibição espiritual e de poder. Essa é uma "alusão aos milagres e às efusões do Espírito que acompanharam a pregação de Pau10" (BÍBLIA DE JERUSALÉM, 1985, nota “e”). Essas efusões do espírito correspondem aos dons (kharísmata), conforme descrito no preâmbulo da carta paulina (1,5-7). Mais adiante, em 12,8-10, Paulo faz uma descrição do que são esses dons:

A um o Espírito dá a mensagem de sabedoria, a outro, a palavra de ciência segundo o mesmo Espírito; a outro o mesmo Espírito dá a fé; a outro ainda o único e mesmo Espírito concede o dom das curas; a outro, o poder de fazer milagres; a outro, a profecia; a outro, o discernimento dos espíritos; a outro, o dom de falar em línguas, a outro ainda, o dom de as interpretar.

No entanto, em 1,4-5 ele menciona que a graça divina cumulou os coríntios de riquezas em toda palavra e todo o conhecimento (en pantì lógo $i$ kaì pásei gnósei). Nesse caso, como interpreta Prior (1993, p. 25-26):

No que se refere à palavra, estariam inclusos dons como profecia, ensino, pregação, evangelização, falar em línguas e interpretação de línguas, e qualquer uso do dom da palavra que contribua para a edificação da igreja. No que se refere ao conhecimento, a igreja como corpo tem acesso a toda a sabedoria, percepção, discernimento e verdade de que necessita; não precisa de gurus especiais para recebê-lo.

Embora seja difícil precisar quais e quantos são exatamente os dons a que Paulo se refere, uma vez que só em seus escritos são encontrados mais de vinte (BORIELLO et al. 2003, p. 200), ao menos é possível compreender que, para o nosso presente estudo, são aos kharísmata que ele se refere quando fala de sua palavra e pregação (o lógos mou kaì tò kérugmá mou).

Por sua vez, o termo "poder" utilizado aqui também está presente em outra passagem que alude às manifestações do espírito nos coríntios. Em 2Cor 12,12 Paulo assinala: "Os sinais que distinguem o apóstolo realizaram- 
se entre vós: paciência a toda prova, sinais milagrosos, prodígios e atos portentosos (dynámesin)”.

2,5: a fim de que a vossa fé não se baseie sobre a sabedoria dos homens, mas sobre o poder de Deus.

Paulo então conclui com a intenção central: a exclusão das considerações de cunho sapiencial humano em detrimento de algo que está acima das produções da mente humana: o poder (unificado) de Deus. Ao excluir de seu escopo a pluralidade das versões humanas de sabedoria, algo que era presente em cidades de forte cultura helenística como Corinto, Paulo quebra a base justificatória na qual se formularam as cisões dentro da igreja dessa cidade.

Porém, em outro sentido, Paulo demonstra sua clara oposição à ideia de que a sabedoria humana não é suficiente, que não se deve confiar nela como balizadora última para a vida, pois há algo maior e mais importante que é o poder de Deus, poder esse evidenciado pelos dons (kharísmata). Como se verifica nas passagens bíblicas seguintes, o que ele diz ter comunicado aos coríntios é a sabedoria de Deus, que é oculta (apokekrumménen) $(2,7)$, revelada pelo espírito $(2,10)$ : “Quanto a nós, não recebemos o espírito do mundo, mas o espírito que vem de Deus, a fim de que conheçamos os dons da graça de Deus" $(2,12)$.

\section{Dois modos de vida distintos}

Nas cartas de Paulo encontramos tanto aspectos essenciais para a compreensão teológica do cristianismo quanto elementos diretivos para uma vida cristã. Isso demonstra como Paulo associa o advento da ressurreição não só a uma nova religiosidade, mas a uma nova forma de vida, diferente tanto da cultura dos gentios quanto da cultura da lei judaica (1Cor 1,23). Portanto, há certamente uma forma de vida associada à sua pregação (kérug$m a)$.

Por outro lado, as escolas filosóficas do período helenístico também estavam associadas a formas de vida específicas, sendo estas relacionadas à escolha (haíresis) da linha filosófica adotada (LONG, 1993, p. 299-300). Dentre essas escolhas, o estoicismo era uma das mais relevantes. 
Sendo assim, apesar do estoicismo ser uma escola filosófica e do cristianismo ser uma religião, ambos têm em comum a característica de implicar modos de vida. No entanto, ainda que Paulo tenha utilizado elementos do vocabulário estoico em suas cartas, tais como "autodomínio" (enkrateía), "sopro/espírito" (pneûma), "atos adequados" (kathékonta), "autopercepção/ consciência" (syneídesis) (ENGBERG-PEDERSEN, 2003, p. 535-558), não é possível afirmar que os modos de vida propostos pelo apóstolo e pelos estoicos possam convergir. Isso porque, dentre algumas diferenças fundamentais, o próprio Paulo propositalmente assinala uma relevante na primeira carta aos coríntios: o rebaixamento da sabedoria em detrimento de uma confiança no poder divino, poder esse manifestado nos dons, nos kharísmata.

Dessa forma, estoicismo e cristianismo se desenvolvem em paradigmas distintos. No caso dos estoicos, o paradigma está envolto pela figura do sábio, não do santo, pois, para eles, é o sábio que demonstra o ideal divino para o ser humano. É em vista disso que podemos entender as seguintes palavras de Kant:

Ora, se considero a moral cristã pelo seu lado filosófico, ela apareceria, comparada com as ideias das escolas gregas, do modo seguinte: as ideias dos Cínicos, dos Epicuristas, dos Estóicos e dos cristãos são, respetivamente, a simplicidade da natureza, a prudência, a sabedoria e a santidade. No tocante ao caminho para aí chegar, os filósofos gregos distinguiam-se entre si de tal modo que os Cínicos achavam para tal suficiente o senso comum ${ }^{11}$, os outros apenas a via da ciência, pensando, no entanto, uns e outros que bastava o simples uso das forças naturais. A moral cristã, que regula a sua prescrição de uma maneira tão pura e severa (como, aliás, deve ser), tira ao homem a confiança de lhe ser perfeitamente adequado, pelo menos nesta vida, mas, no entanto, consola-o pelo facto de podermos esperar, se agirmos tão bem quanto está em nosso poder, que aquilo que não está em nosso poder nos será dado de uma outra maneira, quer saibamos ou não como. (KpV, AA 05:127-128).

\section{Considerações finais}

Após esse estudo comparativo, fica demonstrado que, embora seja possível encontrar em Paulo termos relevantes à filosofia e ao estoicismo

\footnotetext{
11 Apenas discordamos de Kant quanto ao entendimento de que o cinismo baseava-se no senso comum. Atualmente existem estudos que demonstram como a simplicidade ou mesmo rusticidade do discurso cínico na verdade revela uma profunda crítica às convenções sociais, crítica essa fundamentada na explicitação da dissociação do ser humano com o que lhe é de fato natural, cf. KRUEGER, 2000, p. 302-304.
} 
em particular, há um ponto fundamental que se torna um divisor de águas entre estoicismo e cristianismo: o papel da sabedoria. E na medida que estoicismo e cristianismo implicam conversões a modos de vida específicos ${ }^{12}$, pode-se dizer que, em função dessa diferença fundamental propositalmente salientada por Paulo, o cristianismo se afasta definitivamente dos estoicos, uma vez que a vida sábia deixa de ser a meta humana ${ }^{13}$.

\section{Referências}

ARNIM, H. von. (1903-1905). Stoicorum Veterum Fragmenta. Leipzig: Teubner, v. 1-3, 1924, v. 4. (Índices por M. Adler).

AUlO GÉLIO. (2010). Noites Áticas. Trad. José Rodrigues Seabra Filho. Londrina: EDUEL, 2010.

Bíblia de Jerusalém. (1985). São Paulo: Paulinas.

Bíblia: Novo Testamento (Apóstolos, Epístolas, Apocalipse). (2017). Trad. Frederico Lourenço. São Paulo: Companhia das Letras.

BORIELLO, L. et al. (2003). Dicionário de Mística. Trad. B. Lemos, J. M. de Almeida, S. D. C. Reis e U. L. Fleuri. São Paulo: Paulus; Loyola.

CÍCERO. (1959). De Legibus. Georges de Plinval. Paris. Belles Lettres.

CÍCERO. (1967). Das Leis. Trad., intro. e notas de Otávio T. de Brito. São Paulo: Cultrix.

CÍCERO. (1915). De Finibus Bonorum et Malorum. Th. Schiche. Leipzig. Teubner.

CÍCERO. (2012). As últimas fronteiras do bem e do mal. In: CÍCERO, M. T. Textos Filosóficos. Trad. J. A. Segurado e Campos. Lisboa: Fundação Calouste Gulbenkian.

DIÔGENES LAÊRTIOS. (2008). Vidas e doutrinas dos filósofos ilustres. Trad. Mário da Gama. Brasília: Editora Universidade de Brasília.

\footnotetext{
12 Para mais sobre conversão na filosofia antiga e no cristianismo, ver HADOT, 2014, p. 203-213.

${ }^{13}$ Festugière vai ainda mais longe na interpretação da perícope bíblica em questão. Ele salienta o motivo pelo qual Paulo chega a Corinto sentindo grande temor e impotência, que é sua anterior estadia em Atenas (cf. Atos 17,16-34) depois de ter se deparado com a barreira da "sabedoria dos sábios", da "ordem da razão". Nesse caso, a visão de Paulo sobre sabedoria demarca uma importante distinção também em relação ao paradigma filosófico grego (FESTUGIÈRE, 1986, p. 113-126).
} 
ENGBERG-PEDERSEN, T. (2003). Paulo, as virtudes e os vícios. In: SAMPLEY, J. P. (org.). Paulo no Mundo Greco-Romano. Trad. Pe. José Raimundo Vidigal. São Paulo: Paulus, p. 535-558.

FESTUGIÈRE, A.-J. (1986). La esencia de la tragedia griega. Trad. Miguel Morey. Barcelona: Ariel.

FORBES, C. (2003). Paulo e a comparação retórica. In: SAMPLEY, J. P. (org.). Paulo no Mundo Greco-Romano. Trad. Pe. José Raimundo Vidigal. São Paulo: Paulus, p. 113-146.

HADOT, P. (2014). Exercícios Espirituais e Filosofia Antiga. Trad. Flavio Fontenelle Loque e Loraine Oliveira. São Paulo: É Realizações.

KANT, I. (1986). Crítica da Razão Prática. Trad. de A. Morão. Lisboa: Edições 70.

KRUEGER, D. (2000). El desvergonzado y la sociedad: la impudicia de Diógenes en la cultura romana imperial. In: BRANHAM, R. B; GOULETCAZÉ, M.-O (ed.). Los Cínicos. Trad. Vicente Villacampa. Seix Barral: Barcelona.

LONG, A. A. (1993). Intellectuals and Images of the Philosophical Life. In: BULlOCH, A. W. et. al. Images and Ideologies: Self-Definition in the Hellenistic World. University of California Press,.

MAZZAROLlO, I. (2000). Paulo de Tarso: tópicos de antropologia bíblica. Rio de Janeiro: Mazzarollo.

PRIOR, D. (1993). A Mensagem de 1 Coríntios. São Paulo: ABU Editora $\mathrm{S} / \mathrm{C}$.

SÊNECA. (1917-1925). Ad Lucilium Epistulae Morales. Richard M. Gummere. Cambridge. Cambridge, Mass., Harvard University Press; London, William Heinemann, Ltd., v. 1-3.

SÊNECA. (2004). Cartas a Lucílio. 2 ed. Trad. J. A. Segurado e Campos. Calouste Gulbenkian: Lisboa.

The Greek New Testament. (1968). 2 ed. Editado por Aland, K., Black, M., Martini, C.M., Metzger, B.M., Wikgren, A. Stuttgart: Württemberg Bible Society. 